\title{
Evolution of the Ideological Content of the Notion "Giftedness"*
}

\author{
Marina Ivleva \\ Department of Social Philosophy \\ Peoples' Friendship University of Russia \\ 6 Miklukho-Maklaya Street \\ Moscow, Russia \\ E-mail: ivleva_ml@rudn.university
}

\begin{abstract}
The paper aims to trace the evolution of the concept of "giftedness" in the context of accumulation and enrichment of its ideological content with new meanings. We have used the principles and methods of historical, sociocultural and comparative analyses. In particular, the application of the principle of differentiating between the theory and concept helped to identify the subject of research. The paper determines the nature of the concept, its difference from such forms of thought as notion, idea, image. Based on the historical and genetic analysis it became possible to identify and to describe five main stages or ways of conceptualizing giftedness: antique, religious-ethical, empirical, proto-scientific (from the standpoint of particular social sciences), holistic (in the framework of scientific psychology).
\end{abstract}

Keywords-concept; giftedness; conceptualization; ancient stage; religious-ethical stage; empirical stage; proto-scientific stage; holistic stage

\section{INTRODUCTION}

The strategic task facing the modern national educational system in the field of identifying and developing gifted children can be solved, among other things, by the creation by scientists of various branches of knowledge (teachers, psychologists, philosophers, culturologists, sociologists, etc.) of a unified theory of giftedness, which meets all the criteria and features of the scientific theory and performs as a whole all its inherent functions: synthetic, explanatory, prognostic, methodological and practical.

If we analyze the current state of research in the field of giftedness and its development, we can state that there are a number of theoretical approaches to the study of giftedness and a multitude of methods of working with gifted children based on these approaches aimed at satisfying the sharply increased in recent times the needs of social practice. On the other hand, it is the multiplicity and diversity of theoretical positions of scientists, sometimes inconsistent with each other, the lack of a unified theoretical and methodological basis for the study of giftedness, which is an obstacle to fruitful activity in the field of diagnostics and development

*The publication has been prepared with the support of the "RUDN University Program 5-100". of giftedness.

If we turn to the field of psychology, from the point of view of the general methodology of science the system of psychological knowledge of giftedness by its structural properties has not yet reached the level of theory, but it is a concept. The process of its theorization can be promoted by researching the conceptual foundations of the existing psychological concept of giftedness in the historical and genetic aspect, by studying the formation of its philosophical foundations. In the history of the development of science, the concepts, as a rule, genetically precede the theory, creating the basis for its formation. If the concept at a certain stage of its development is transformed into a scientific theory, the very process of such transformation acts as theorizing the concept, while the process of concept formation is the conceptualization of the corresponding notions, ideas, perceptions, value systems, cultural stereotypes.

The exploration of the process of conceptualization or the creation of a concept allows us to depict both rational and irrational ways of developing a particular problem, to understand the essence of the phenomenon under study in the combination of conceptual, sensory and value aspects of its representation in the consciousness of both an individual and a group of people. This exploration opens new possibilities for interpreting the embedded (encoded) in the concept senses and for constructing the new ones.

In the semantic sense, the concept of giftedness is associated with such theoretical concepts as "makings", "abilities", "activity", "creativity". Each of these concepts implies a corresponding approximation to the problem of giftedness.

In a number of previous works, we solved the problem of distinguishing the concept from other types of mental formations, in particular, theory [1]. It became possible to develop a clear idea of what the concept really is, what its structure is. The next important task on the way of forming the philosophical foundations of psychological concept of giftedness is to clarify the nature of the concept, its difference from such forms of thought as notion, representation, image, social construct, etc. In this article, we will dwell in more detail on the results of philosophical and 
historical research of the concept of giftedness as one of the forms of representing giftedness in subjective reality.

\section{DIFFERENT APPROACHES TO THE INTERPRETATION OF THE TERM "CONCEPT"}

Notional and conceptual apparatus of any science contains in its structure both specific terms used only in this language and expressing special notions of this science, and nonspecific terms that can be used in other sciences and in everyday communication of people. In this case, the notions expressed by these terms can also be nonspecific, they can coincide in their content with the ordinary notions used in everyday practice. Along with this, there are specific notions expressed in terms that have analogues in natural language and ordinary consciousness. It is to such notions that the notion of giftedness refers. At that, every person knows (or at least believes that he knows) what giftedness is. In psychological science this notion, as we have shown in the result of the carried research, has a whole set of specific meanings, based on theoretical grounds, but the same notion in ordinary consciousness has different nature. In the second case, it is more correct to speak not of the notion, but of the concept of giftedness [2].

The word "concept" (from the Latin conceptus perception) in the literal, original sense means the act of "grasping" by the cognizing subject the meaning of a thing in the unity of speech utterance. This term was introduced by the scholastics in the 12th century in the context of analyzing the problem of universals (the problem of the ontological status of general concepts). However, in modern semiotics, the term "concept" has significantly expanded its meaning.

Today, the concept is most often understood as the complex mental formation of practical (everyday) philosophy, which is the result of the interaction of a variety of cultural factors, including such ones as national tradition, folklore, ideology, religion, lifestyle, art, value system. In its meaning, the concept can correspond to the notion, but it differs from it in greater uncertainty, vagueness of semantic shades, although, perhaps, in richer content. As N.D. Arutyunova writes, the concepts form "a sort of cultural layer mediating between the man and the world" [3]. S.H. Lyapin defines the concept as "multidimensional culturally significant socio-psychic formation in the collective consciousness, objectified in one or another linguistic form" [4]. It is noted that the boundaries of this socio-psychic formation are indistinct and vague and that not every cultural and linguistic concept necessarily corresponds to a certain lexical unit. It is important to emphasize this fact considering the tasks of our study. Symmetry between the conceptual and semantic spheres of natural language, as a rule, is absent, as is noted by some researchers [5]. In other words, the same concept can be expressed in different terms, or it may not have a certain terminological correspondence, but can be expressed through a descriptive complex.

Be that as it may, the concept has an ideal nature. A. Vezhbitskaya, considering the concept as "an object from the world of "Ideal", having a name and reflecting certain culturally conditioned man's ideas about the world of
'Reality', distinguishes two types of concepts: elementary concepts that are supranational in character, they are congenital and universal, and culturally specific, which are the products of human culture and collective consciousness [6] [7].

In contrast to the notion, which is the product of certain mental, logical procedures, the concept is the result of a holistic perception of the subject in all the diversity of its concrete manifestations, "a unit of thought acting as an integral, undivided reflection of the fact of reality, regardless of its external relation to other units; in the structural plan it is opposed to logical constructions, i.e. to any combination of concepts, expressed in language combinations, which can be both a complex notion and a complex combination and a logema of any kind" [8].

Representatives of the cognitive-linguistic approach, both foreign and domestic, understand the concept from the point of view of contained in it information about the relevant object or objects of reality [9]. V.N. Telia treats the concept as "what we know about the object, in the entire extension of this knowledge, that is, the whole body of knowledge about what is indicated in all its connections and relations, and it answers the question "What is known about this?"[10]. R. Jakendoff treats the concept as a 'mental structure', reflecting and fixing the experience, and also as a construct of the ontological category [11]. "A Brief Dictionary of Cognitive Terms" defines the concept as a phenomenon that corresponds to "the notion of the meanings which people operate in the processes of thinking and which reflect the content of experience and knowledge, the content of the results of all human activity and the processes of cognition of the world in the form of some "quanta" of knowledge" [12].

As for the connection of the concept with the word, in this issue the positions of the researchers diverge. A significant part of the representatives of the cognitivelinguistic approach does not connect each concept with the word: only a part of the concepts, from their point of view, has a verbal form of representation, while others are represented in the psyche by other (basically, figurative) mental representations - pictures, schemes, etc. [13]. Thus, Z.D. Popova and I.A. Sternin, while developing the cognitivistic interpretation of the concept, define it as a global thinking unit, a quantum of structured knowledge, an ideal entity that is formed in the mind of man [14]. Being originated in the form of a primary concrete image, the concept in the process of cognitive activity and communicative practice of man gradually acquires all the new conceptual levels, complicating its structure, building up all the new conceptual layers, as a result of which its content becomes more and more rich [15] [16].

However, the most common position is that the link between the concept and linguistic expression is not excluded, although it is not mandatory. In this case, the concept can be expressed in a word, a phrase, a phraseological unit, a sentence, a text, "it can be expressed in speech descriptively" [17] [18]. Y.S. Stepanov believes that the concept can be found in "some context - or text - of any 
nature. This may be a saga, a myth (even though it is retold verbally in countless different variations) ... "[19].

Another position is to interpret the concept precisely as a meaning, as the content of the linguistic sign [20]. Thus, E. S. Kubryakova defines concepts as "images of the content of signs" [21]. A close definition of the concept is given by I.A. Sternin and G.V. Bykov: this is a "mental image, called a lexical unit" [22]. O.L. Cherneyko considers the concept as a mental construct (Gestalt), standing behind the abstract name [23]. N.A. Semkina believes that the concepts "always have a linguistic expression", according to I.Y. Vertelova, conceptualization in order "to be fixed, ... finds completion in the linguistic nomination" [24] [25].

G. I. Berestnev adheres to the opposite point of view, he believes that the concept is strictly "iconic" [26]. The iconicity of the concept is manifested in the fact that it is characterized only by the content tools and "does not have its own special expression tools" [26].

It seems that the second position is the most realistic out of the listed ones: exploring the most important cultural concepts which have a long history and are deeply embedded in the history of human thought, to which the concept of "giftedness" refers, we will inevitably face the fact of the absence of a single verbal designation, with the variability and complexity of expressing the concept in language.

This is largely due to the variability of the very ways of conceptualizing giftedness, among which one can distinguish the ancient, religious-ethical, empirical, proto-scientific (from the standpoint of specific social sciences), holistic (within the framework of scientific psychology) ways.

\section{The MaIn Stages IN THE EVOLUTION OF THE \\ IDEOLOGICAL CONTENT OF THE CONCEPT GIFTEDNESS}

The analysis shows that at each of the selected stages of developing the concept of giftedness, there occurred the accumulation of ideological prerequisites and the enrichment of the contents of the concept of giftedness with new meanings.

For example, in the paradigm of ancient thinking, there is no notion of giftedness as outstanding inborn qualities of a person, which serve as prerequisites for the formation and development of abilities manifested in successful activity in a certain sphere, which allows a person to achieve certain (including, perhaps, social) advantages over others. At the same time, concepts corresponding to individual semantic components of this notion can be found in the system of anthropological views of antiquity. A whole series of ideological preconditions for the concept of giftedness can be found in the philosophical doctrines of the Hellenistic era. Thus, the philosophers of Late Stoi (Seneca, Epictetus, Marcus Aurelius) developed the early antique idea of human dignity, laying in its foundation an in-depth understanding of sociality, individual differences and learning through imitation [27]. In the extant works of Plotinus (204/205 - 270 $\mathrm{AD})$ his doctrine of reflection, in the context of our study, deserves attention, according to which the soul constantly monitors its work and serves as a "mirror" for itself. Later, the idea of reflection was placed in the basis of introspective psychology of consciousness.

As for the evolution of the ideological content of the concept of "giftedness" in Judeo-religious philosophy, it occurred around the central problem - the problem of salvation, which in its turn is a historically concrete modification of the basic issue which lies at the root of man's interest to the problems of his own essence and existence, the question of death and immortality. Therefore, within the framework of Christian anthropology, a person is viewed from the point of view of his attitude toward God, mainly in connection with the problem of salvation. It is this way that the problems of the definition of man, the relationship of soul and body, the dignity and insignificance of man, etc., are interpreted [28]. The development of abilities is based on grace as the gift of God to man, as the giftedness of man given by God, and the source of abilities is considered to be the God-likeness of man.

If we turn to the analysis of the next, third stage of forming the concept of giftedness, we can identify the emergence of a number of new ideological elements. This stage we will conditionally call 'functionally-empirical'. Historically it corresponds to the period of the late Middle Ages (Renaissance) - the beginning of modern times. This stage is characterized by the transition from abstract anthropological approaches to concrete-empirical and functional ones, by the desire to interpret the developing concepts in the context of social practice, to 'decompose' the concept into measurable components. At this stage, the complete anthropological systems were replaced by attempts to study certain specific functions of human activity, in the context of specific areas of activity.

The content of the fourth stage, which can be conditionally called proto-scientific, is the active development of the concepts of giftedness in various spheres of human thought (including, mainly, philosophy, pedagogy, cultural studies, scientific anthropology, sociology, etc.), as well as psychology that precedes and prepares the emergence of a scientific psychological theory of giftedness. Chronologically, this phase covers the period from the late 18 th - early 20th centuries, since, as was shown in the previous works of the author the active accumulation of conceptual prerequisites for theorizing the psychological concept of giftedness continues up to the present time, while the unified theory of giftedness, within which all internal contradictions would be finally eliminated and all existing approaches would be taken into account, has not yet been created [29].

Nevertheless, the fifth stage, which chronologically partly coincides with the previous one, since it began in about the middle of the nineteenth century, can rightfully be called a scientific one, because the process of conceptualizing giftedness continues already in the context of psychological science, using scientific methods, including the methods of empirical verification of hypotheses put forward by observation and experiments.

Along with the further expansion of the notion and the inclusion into it of additional criteria apart from the 
traditionally accepted academic success of children, significant changes in methodology and terminology take place. Innovative educational programs, in which the study of the possibilities of gifted children is combined with an analysis of their achievements, are being developed, and the areas of investigation extend to such specific qualities of children's personality as leadership, methods of decisionmaking, setting goals, planning activities, social responsibility, etc. Studies of the aesthetic gifts of children are becoming very popular. It is natural to abandon the generally accepted methods of testing and to develop the new, innovative ways to determine the potential of children.

\section{CONCLUSION}

Taking as a basis the understanding of a concept developed in social and human sciences, the concept being defined as the result of individual and collective cognition, which reflects both the rational and irrational aspects of the studied phenomena (in our case, giftedness) and unites in its structure the image, notion and value, we traced different periods of content composition of the concept of giftedness, which made it possible to identify the specifics of this process in a historical perspective and, as a consequence, to take another step towards understanding the nature and the essence of this phenomenon.

Each of the identified and described above paths has its own historical profile, and at the same time one can talk about their intertwining, mutual influence, the result of which is the exchange of semantic elements between different spheres of human knowledge. The result of these processes is the formation of the modern concept of giftedness.

\section{REFERENCES}

[1] M.L. Ivleva, N.L. Bagramiants, V.Y. Ivlev, M.B. Oseledchik, Methodological Principles of the Study of the Philosophical Foundations of Psychological Conceptions of Giftedness // Proceedings of the 2016 3rd International Conference on Education, Language, Art and Inter-cultural Communication (ICELAIC 2016). Advances in Social Science, Education and Humanities Research. Paris: Atlantis Press, 2017. Vol. 40, pp. 48-52

[2] M.L. Ivleva, Foundations of the Psychological Conception of Giftedness. M .: MSTU "MAMI" 2011.

[3] N.D. Arutyunova, Introduction // Logical analysis of the language. Mental actions. - Moscow: Nauka, 1993, pp. 3-5.

[4] S.H. Lyapin, Conceptology: to the development of the approach // Concepts. Scientific works of the Centroconcept. Issue. 1. Arkhangelsk: Publishing house of Pomor State University named after M.V. Lomonosov, 1997, pp. 11-35.

[5] G.G. Slyshkin, Linguistic and cultural concepts and meta-concerts. Volgograd: Peremena, 2004, p.15.

[6] P.M. Frumkina. Conceptual analysis from the point of view of the linguist and psychologist: (concept, category, prototype) // STI. Ser. 2. Information processes and systems. -1992 , No.3, p. 6.

[7] A. Wezhbitskaya, Understanding cultures through key words // Semantic universales and the description of languages. M.: Shk. "Languages of Russian culture", 1999, p. 217.

[8] P.V. Chesnokov, Basic units of language and thinking. Rostov-onDon: Rostov Publishing House, 1966, p. 14.
[9] L.M. Kovaleva, The role of SELF in the conceptualization of I / L.M. Kovaleva, L.G. Aleksandrova // Cognitive analysis of the word. Irkutsk: IGEA Publishing House, 2000, pp. 103 - 126.

[10] V.N. Telia, Russian phraseology. Semantic, pragmatic and linguocultural aspects / V.N. Telia. M.: Yaz. Rus. culture, 1996, pp. 97, 100 .

[11] R. Jackendoff, Semantics and Cognition / R. Jackendoff. Cambridge, Mass. L.: MIT Press, 1993, p. 78.

[12] A Brief Dictionary of Cognitive Terms / Ed. E. S. Cubryakova. V. 3 [and others]. Moscow: MSU, 1997, p. 9.

[13] E.S. Kubryakova, Concept // A brief dictionary of cognitive terms / Kubryakova E.S., Demyankov V.Z., Pankrats Y.G., Luzina L.G. Moscow: MSU Publishing House, 1996, p. 96.

[14] Z.D. Popova, I.A. Sternin, The concept of "concept" in linguistic studies. Voronezh, 1999, p. 4.

[15] I.A. Sternin, Can a linguist model the structure of a concept? // Cognitive semantics: Materials of the Second Intern. school-seminar on cognitive linguistics. Part 2. Tambov: Publishing House of TSU named after G.R. Derzhavin, 2000, p. 144.

[16] Z.D. Popova, I.A. Sternin, Essays on cognitive linguistics. Voronezh: Istoki, 2001, p. 71.

[17] A Brief Dictionary of Cognitive Terms /Ed. E. S. Cubryakova. V. 3. [and others]. Moscow: MSU, 1997, p. 90.

[18] T.B. Novikova, Types of cultural concepts // Linguodidactic problems of intercultural communication: proceedings : anniversary edition. / Ed. T.V. Maksimova. Volgograd: VSU Publishing House, 200, p. 190.

[19] Y. S. Stepanov, Constants: Dictionary of Russian culture / Y.S Stepanov. - 2nd ed., rev. and supplemented. - M.: Academ. project, 2001, p. 75.

[20] V.V. Krasnykh, From the concept to the text and back (to the question of psycholinguistic text) // MSU Press, Series 9. Philology, 1998, No.1, p. 55.

[21] E.S. Kubryakova, On a fragment of the conceptual analysis of the word memory // Logical analysis of the language: Cultural concepts. M.: Nauka, 1991, p. 89

[22] I.A. Sternin, Concepts and lacunas / I.A. Sternin, G.V. Bykova // Linguistic consciousness: Formation and functions: proceedings / Ed. N. V. Ufimtseva. M., 1998, p. 56.

[23] L.O. Cherneyko, Linguophilosophical analysis of the abstract name / L.O. Cherneyko. M.: 1997, p. 301.

[24] N.A. Semkina. Concepts and their links in the text. // Text and Discourse: Traditional and Cognitive-functional aspects of research: proceedings / Ed. L. A. Manerko. - Ryazan: RSPU, 2002, p. 113.

[25] I. Y. Vertelova. Conceptualization of the inner world of man in the Russian language: mental states of sadness: Thesis of diss. ... cand. of Philology, Kaliningrad, 2001, p. 14

[26] G.I. Berestnev. On the "new reality" of linguistics / G.I. Berestnev // Fil. science. 1997, No 4, pp. 47-55.

[27] A. Stepanova, The Philosophy of Ancient Stoi. St. Petersburg, Aleteya, 1995, pp. 134-139.

[28] O.V. Chistyakova. Philosophical-anthropological grounds of Self and God (as Other) relationship in Christian and Islam Discourses. In the context of interreligious communications // Proceedings of the 2017 4rd International Conference on Education, Language, Art and InterCultural Communication. (ICELAIC 2017). Advances in Social Science, Education and Humanities Research, Volume 142. Moscow, Russia, 17-18 October, 2017. Paris: Atlantis Press, 2017. P. 734 -738.

[29] M.L. Ivleva, V.Yu. Ivlev. Principal approaches of modern psychology to constructing giftedness // "Proceedings of the 2017 2nd International Conference on Contemporary Education, Social Sciences and Humanities". (ICCESSH 2017). Part of the series ASSEHR. Moscow, Russia, V.124, p.1176-1180. 